UC-41

Issued: September 1984

$L A--10246-M S$

DE85 005230

\title{
Uranium Internal Exposure Evaluation Based on Urine Assay Data
}

James N. P. Lawrence

DISCLAIMER

This report was prepared as an account of work sponsored by an agency of the United States Government. Neither the United States Government nor any agency thereuf, nor any of their employees, makes any warranty, express or implied, or assumes any legal liability or responsibiilty for the accuracy, completeness, or usefulness of any information, apparatus, product, or process disclosed, or represents that its use would not infringe privately owned rights. Reference herein to any specific wmmercial product, process, or service by trade name, trademark. manufacturer, or otherwise does not necessarily constitute or imply its endorsement, recommendation, or favoring by the United Statcs Government or any agency thereof. The views and opinions of authors expressed herein do not necessarily state or reflect those of the United States Government or any agency thereof. 
URANIUM INTERNAL EXPOSURE EVALUATION BASED ON URINE. ASSAY DATA

by

James N. P. Lawrence

\begin{abstract}
The difficulties in assessing internal exposures to urarium from urine assay data are described. A simplified application of the ICRP-30 and ICRP Lung Model concepts to the estimation of uranium intake is presented. A discussion follows on the development of a computer code utilizing the ICRP-30-based uranium elimjnation model with the existing urine assay information. The calculated uranium exposures from 1949 through 1983 are discussed.
\end{abstract}

A fluorometric urine assay program for natural or depleted uranilir was initiated at Los Alamos in 19.49, purely as an indicator of exposure. During 1953 a radiometric uranium urine assay technique was developed to provide an indicator of exposure to enriched uranium. During the 1950's and early 1960 's, urine assay results exceeding 100 micrograms per liter by fluorometric analysis or $100 \mathrm{dis} / \mathrm{min}$ per liter by radiometric analysis were considered indications of exposure, which, if repeated, required an investigation and eìmination of cause. Formal evaluations of each individual's annual uranium exposure were not initiated until 1967.

The routiria evaluation of internal exposures to uranium compounds is a complicated process fraught with large uncertainties. At least four factors contribute to the complications: (1) different solubilities of uranium compounds, (2) complex urinary elimination patterns, (3) consideration of nephrotoxic and radiologicai damage limits depending on isotopic enrichment, and (4) economic restrictions; on frequency of urine analyses.

\title{
Different Solutilities of Uranium Compourids
}

The various uranium compounds encountered at Los Alamos cover a wide range of solubilities. In general, hexavalent uranium compounds are the most 
soluble, and tetravalent uranium compounds are less soluble. For internal dosimetry considerations, classification according to the ICRP Lung Model clearance rates is probably the most satisfactory. In WASH-125l, "Applications of Bioassay for Uranium," ${ }^{1}$ several chemical forms are classified according to this criterion. Class $D$ compounds (eliminated from the lungs with half-times measured in davs) include uranium hexifluoride, uranyl nitrate, uranyl acetate, uranyl chloride, uranyl fluoride, uranyl sulfate, and uranium trioxide. Class $W$ compounds (lung elimination half-time measured in weeks) include uranium tetrafluoride, uranium oxide $\left(U_{3} 0_{8}\right)$, uranium dioxide, uranium tetraoxide, and ammonium diuranate. Class $Y$ compounds (lung elimination half-time measured in years) include uranium carbide and high-fired uranium dioxide.

Los Alamos experience, as evidenced by urinary excretion, suggests that all chemical forms show a significant degree of early rapid solubility. Even persons with airborne exposure to uranium oxide resulting from machining operations or fires of chips and brickettes excrete (via the urine) measurable quantities of uranium during the day of uptake, beginning minutes following the inhalation.

\section{Urinary Excretion Patterns}

The primary data on urinary excretion was obtained from two human injection studies. 2,3 In the earliest study, seriously ill patients were injected with hexavalent uranium (uranyl nitrate hexahydrate). In the second study, eight terminally ill brain tumor patients were injected; six were injected with hexavalent uranium and two were injected with tetravalent uranium (uranium tetrachloride). The results of both studies using hexavalent uranium were quite similar. About $72 \%$ of the uranium was excreted via the urine in the first 24 inours. The two patients injected with tetravalent uranium excreted only about $20^{\circ}$ in the first 24 hours. After the first day, the uranium excretion followed a power function elimination equation, proportional to $t^{-1.5}$, where $t$ is expressed in days. In all cases no measurable uranium was found in the feces.

ICRP $-10^{4}$ adopted the foliowing urinary excretion equations based on transportable (soluble) fuins of uranium:

$$
Y_{u}=0.8 \text { (on the day of uptake) and }
$$


$Y_{u}=0.1 t^{-1.5}(t \geq 1$ day $)$

where $Y_{u}$ is the fraction of the uranium originally in the blood that is excreted per day, and $i$ is the time since uptake in days.

In using these excretion equations, it is presumed that the uranium taken into the tody is soluble and rapidly transported to the bloodstream. The first accidental inhalation cases and animal experiments confirmed this presumption for soluble forms of uranium.

The data on insoluble forms of urunium are sparse. As indicated above, Los Alamos urine assay data indicate that a part of any inhaled uranium acts as though it were soluble, and that portion would presumabiy follow the above elimination equations, once it had reached the blood. To further confuse the issue, ICRP $-30^{5}$ presents retention equations for uranium (which has entered the transfer compartment, i.e., blood) in bone, kidney, and other organs, and the amount going directly to urinary excretion from the blood. For simple retention equations with no build-up term, the excretion equations are the negative derivatives of the retention functions. Thus, according to ICRP-30, for uranium in the blood, 0.223 is deposited rapiuly in the bone, 0.12052 is deposited rapidly in the kidney, 0.12052 is deposited rapidly in other organs, and 0.53596 is excreted directly (presumably by urine to blood on the day of uptake). For each acute uptake (to the blood) the fractional daily excretion equations are

$$
\begin{aligned}
& Y_{\text {BONE }}=0.00693 \mathrm{e}^{-i} 20^{t}+0.00000319 \mathrm{e}^{-\lambda} 5000^{t}, \\
& Y_{\text {KIDNEY }}=0.0139 \mathrm{e}^{-1} 6^{t}+0.00000024 \mathrm{e}^{-\lambda} 1500^{t}, \text { and }
\end{aligned}
$$

\footnotetext{
* Much of the ralculational formalism presented in this paper is based on the ICRP-30 retention equations for uranium and the ICRP Lung Model. In both of these models, the coefficients and exponents of any single term is expressed to only one or two significant figures. In order for the reader to trace the development of the equations and not be confused by rounding adjustments, the full decimal expressions have been retained in the text. It should be kept in mind that the final calculated values of intake, etc., are only valid to at most two significant figures or more probably to one significant figure.
} 


$$
\gamma_{\text {OTHER }}^{\text {ORGANS }}=0.0139 \mathrm{e}^{-\lambda} 6^{t}+0.00000024 \mathrm{e}^{-\lambda} 1500^{t},
$$

$$
\text { where } \begin{aligned}
& \lambda_{20}=0.693 / 20, \\
& \lambda_{6}=0.693 / 6, \\
& \lambda_{5000}=0.693 / 5000, \\
&{ }_{1} 1500=0.693 / 1500, \text { and } \\
& t \text { is time since intake (days). }
\end{aligned}
$$

Compered with the ICRP-10 formalism, these equations predict less excretion on the day of intake and on the first and second days, but. nore excreted on days after day 3, with about a factor of 5 more by dav 14 .

For inhalation exposures the picture becomes much more complicated. The above excretion equations require significant modification when the dynamics of the ICRP Lung Model ${ }^{6}$ are considered. The later section of this paper, entitled "ICRP-30 and ICRP Lung Múdel Uranium Elimination," presents a somewhat simplified approach, which should be a good representation of the models for time periods up to 100 days. Any attempt to back-calculate inhaled quantities of uranium rom urine assay results requires specific assumptions on ( 1 ) the ratio of the Class $D$ to Class $W$ airtorne uranium and (2) the dates of inhalaticn with respect to the urine sample date.

In the book Uranium, Plutonium, Transplutonic Elements, ${ }^{7}$ pp. 264-265, a development is presented to determine for natural or depleted uranium the "postulated maximum total urinary excretior" for the case of continuous workday inhalation at the Maximum Permissible Concentration in air ( $\mathrm{MPC}_{a}$ ), based on ICRP Committee II $(1959)^{8}$ concepts. For weekdays, excluding Monday, by ICRP Committee II (1959) standards, the "postulated maximum total urinary excretion" is $0.49 \mathrm{mg} /$ day. On Mondays (since there is rio intake on Saturday or Sunday), the "postulated maximum tutal urinary excretion" is $0.08 \mathrm{mg} / \mathrm{day}$.

The following is a development for Class D compounds using ICRP-30 and ICRP Lung Model concepts, paralleling the develofment referenced above. The Derived Air Concentration (DAC) is the ICRP-30 equivalent of the MPC $a$ and is based on radiation exposure to th. applicable organs. The DAC in $\mathrm{Bq} / \mathrm{m}^{3}$ is the same for ${ }^{238} \mathrm{U},{ }^{236} \mathrm{U},{ }^{235} \mathrm{U}$, and ${ }^{234} \mathrm{U}$. so that in terms of activity, the 
ssotopic mixture in natural, depleted, and enriched uranium does not matter. For these uranium isntopes, the $D A C=20 . B q / m^{3}=5.4 \times 1 U^{-4}: C i / m^{\prime}$ (true curie), which compares with the $M P L_{a}$ value of $7 \times 10^{-5}$ :Ci/m (special curie) for natural uranium.* From the "Reference Man" (ICRP-23), "man" inhales $9.6 \mathrm{~m}^{3}$ in an 8-hour workday for "light activity." According to the ICRP Luny Model for Class D materials, 0.4837 of the uranium inhaled goes to the transfer compartment (blood). Thus, in one workday the maximum amount going to the blood is $5.4 \times 10^{-4}: . \mathrm{Ci} / \mathrm{m}^{3} * 9.6 \mathrm{~m}^{3} /$ day* $0.4837=2.5 \times 10^{-3} \quad \mathrm{Ci} /$ day.

According to ICRP-30, for short-term eliminat iun (less than one-day-transfer half-time) of Class $D$ materials, the fraction in the blood going to the bone is 0.223 , the fraction in the blood going to the kidney is 0.12052 , the fraction in the blood going to other organs is 0.12U52, and the fraction in the blood going directly to urine is 0.53596. Thus the prompt (not deposited) urinary excretion would be $2.5 \times 10^{-3}$..Ci/day*0.53596 $=1.3 \times$ $10^{-3} \cdot \mathrm{Ci} /$ day.

In ICRP Committee II (1959) report, the "average working day retention" was reduced by $5 / 7 * 50 / 52$, but ILRP-30, Part 1, p. 9, does not use this reduction factor, and it will not be used in this development. In the ICRP-30 retention equacions for uranium, there are two long-term (but small-magnitude) components of 5000-day and 1500-day haif-times. Ignoring these long half-time terms [because it is unlikely that they will equilibrate in a practical (ltss than 1 year) sterdy-state conditicn], the fraction entering and exiting (i.e., as much "in" as joes "out") the bone, kidney, and other organs of that in the blood under quasi-steady-state conditions is $0.2+0.12+0.12=0.44$. The steady-state uriniry excretion from these compartments is $2.5 \times 10^{-3}$..Ci/ day*0.44 $=1.1 \times 10^{-3}: \mathrm{Ci} /$ day. Thus, the "postulated maximum urinary excretion would be $2.4 \times 10^{-3}$ iCi/day $(3.4 \mathrm{mg} /$ day for natural uranium or $5.1 \mathrm{mg} /$ day for depleted uranium) if the urine sample wis coljected during a "non-Moriday" workday. If the urine sample was collected on a Honday, the

\footnotetext{
*ICRP Committee II (1959) acknowledged a "special curie" definition for natural uranium. One curie of natural uranium consisted of l curie ${ }^{235} \mathrm{u}$ lus 1 curie ${ }^{234} \mathrm{U}$ plus 0.0046 curie ${ }^{25} \mathrm{U}$. Thus, the MPC or $7 \times 10^{-5} \mathrm{iCi} / \mathrm{m}^{2}$ for natural uranium was actually $1.4 \times 10^{-4}, \mathrm{i} \mathrm{i} / \mathrm{m}^{3}$ of true activity and corresponded to $0.21 \mathrm{mg} / \mathrm{m}^{3}$ of natural uranium. In comparing the DAC and MPC for natural uranium, in terms of true activity, the DAC is $\sim 4$ times the MPC ${ }_{a}^{a}$.
} 
short-term excretion term would be absent, and the expected urinary excretiur. would be $1.1 \times 10^{-3} \mathrm{uCi} /$ day $(1.6 \mathrm{mg} /$ day for natural uranium and $2.4 \mathrm{mg} / \mathrm{day}$ for depleted uranium). Note that these values are much larger than the values derived from ICRP Committee II (1959) diata, which probably reflect, in part, the DAC/MPC ${ }_{a}$ ratio. (All daily excretion rates must bu divided by $1.4 \mathrm{~L} /$ day $^{9}$ to obtain the expected concentration in $\mu \mathrm{Ci} / \mathrm{L}$ or $\mathrm{mg} / \mathrm{L}$ ).

\section{Considerations of Nephrotoxic Limits for Soluble Uranium}

In 1964 I. S. Eve published ${ }^{10}$ a rationalization of the ICRP $-6^{l l}$ chemical toxicity limit for soluble natural wranium (i.e., daily inhalation of not more than $2.5 \mathrm{mg}$ ). She started by considering an acute inhalation of 13 weeks' ( 65 warkdays') allowance in a single workday at the radiological MPC a ( $\mathrm{x}$ $10^{-5}$.. $\left[i / \mathrm{m}^{3}\right)$ for soluble natural uranıum. Specifically, she considered the inhalaiion of $10 \mathrm{~m}^{3}$ of air at a concentration of $65 \times 0.21 \mathrm{mg} / \mathrm{m}^{3}$ to give $136 \mathrm{mg}$ inhaled in a single incident. Using the 1964 models (i.e., 25\% of the scluble mount intraled going to the blood and 50\% of the amount in the blood going to 1 itter of urine in less than 24 hours), she predicted a urinary concentration of $17 \mathrm{mg} / \mathrm{L}$. She compared this urine level with s'me human accidental exposure cases, where albuminuria was observed at urine levels of $2 \mathrm{mg} / \mathrm{l}$, arid concluded that $17 \mathrm{mg} / \mathrm{L}$ would be unjustifiably high. Thus, she ruled out a 13-week dose all in one exposure. Without further embellishments she stated: "It would be reasonable therefore that 1 day's total exposire could be allowed ir a single intake; this quantity is $2.1 \mathrm{mg}$ in the air breathed (or to allow some free play $2.5 \mathrm{mg}$ )." Thus, the ICRP-6 limit for inhaled soluble naturai uranium was actualiy based on a single day's inhalation at the radiological $\mathrm{MPC}_{a}$, with a ? эrge amount of conservatisria built in.

On the basis of animal studies, C. Voegt]in and $H$. C. Hodge ${ }^{12}$ state that $0.003 \mathrm{mg} / \mathrm{g}$ of natural uranium in the kidney tissue is the limit to avoid kidney damage. For a $292.5 \mathrm{~g}$ kidney [average reference adult male, $310 \mathrm{~g}$, and adult female, $275 \mathrm{~g}($ ICRP--23)], this gives a kidney burden of $0.88 \mathrm{mg}$ of uranium. Using the ICRP-30 retention equation, the fraction deposited in the kidney from the blood is 0.12052, which gives the maximum blood level as $7.3 \mathrm{mg}$. The amount. which could be inhaled to reach this blood level depends on the solubility class, according to the ICRP Lung Model. For Class D compounds, the fraction of that inhaled going to the blood (with half-time 
less than 1 day) is 0.4837 , which would allow $7.3 / .4837=15.1 \mathrm{mg}$ of uranium to be inhaled. For Class $W$ coinpounds, the fraction of that inhaled going to the blood (with a half-time of 1 day or less) is 0.0905 . (I ignored the 50-day half-time components, since the toxic limit depends initially on the short-term transfer, i.e. acute effects). Thus, for Class $W, 7.3 / 0.0905=$ $80.5 \mathrm{mg}$ of uranium could be inhaled for toxicity considerations. Since the ratio of Class $D$ to Class $W$ compounds is usually not known, prudence suggests treating all uranium inhalations to be Class $D$ compounds for chemical toxicity considerations.

For natural uranium $15.1 \mathrm{mg}$ is $0.011 \mu \mathrm{Ci}$, for depleted uranium it is $0.0071 \mu \mathrm{Ci}$, and for $95 \%$ enriched uranium, it is $1.07 \mu \mathrm{Ci}$, based on the true curie definition and the typical isotopic compositions of these materials. Using the $9.6 \mathrm{~m}^{3}$ /day for an adult male (ICRP-23) and the DAC (ICRP-30) for uranium isotopes (in natural and depleted uranium) of $20 \mathrm{~Bq} / \mathrm{m}^{3}$, the daily allowed inhalation, based on radiological considerations, is $20 \mathrm{~Bq} / \mathrm{m}^{3} * 2.7 \times$ $10^{-5} \mu \mathrm{Ci} / \mathrm{Bq} * 9.6 \mathrm{~m}^{3} /$ day $=0.0052 \mu \mathrm{Ci} /$ day. Since this value is slightly more restrictive than the toxicity limit for depleted uranium, the inhalation for 8 hours at the DAC for uranium is appropriate for both toxicological and radiological considerations.

\section{Economic Restrictions on Urine Sampling Frequency}

Abour 60 persons at the Laboratory (1984) have a potential for inhalation exposures of depletej or enriched uranium because they are routinely involved in metallurgical, chemical, ur machining operations with uranium. Because of the early rapid urinary excretion of uranium, in order to most completely evaluate uranium uptake by individuals from urine assay data, it would be necessary to analyze daily urine samples. From an economic viewpoint (i.e., the cost of daily analyses for 60 pecple), this is not practical (to say nothing of the employee morale problems, which would be created by daily sampling requirements).

Our experience with the present uranium urine sampling program has indicated that inhalation exposures above the permissible limits are infrequent and small. The present sampling program requires the submission of urine samples biweekly (i.e., once every 2 weeks). Historically, the samples were usually submitted on Fridays, just before the employees left. Collection on Fridays provides the greatest sensitivity for detection, but complicates 
the calculation of uptake because small uptakes on the day of and the day before the collection result in relatively large excretion rates.

The biweekiy sampling rate has proved to be economically satisfactory, but somewhat questionable in terms of the overestimate of uptakes, caused by Friday sampling.

\section{Previous System for Evaluating Uptakes}

The previous uranium uptake evaluation procedure was established by $A$. Valentine (Los Alamns Health Physicist) in 1967 and is based on the method reported by 5 . Jackson. 13 Jackson's method required collection of urine samples on Mondays before the employee entered an area where an uptake could accur, thus avoiding the high excretion rate on the diy the sample was collected. Using ICRP Committee II (1959) concepts, Jackson calculated the expected excretion rates (for enriched and natural uranium) for a maximum permissible organ burden in bone and lung. Dividing the actual urine assay results by these calculated expected excretion rates gave the fractional organ burden represented by that urine sample. Jackson recognized that an uptake during the week preceding the urine sample collection could cause elevated urine uranium excretion over the steady-state maximum permissible organ excretion, but felt this overestimation tolerable. The Los Alamos application of Jackson's method retained the urine sample collection just before leaving work on Friday, thus resulting in larger average excretion rates than vould have resulted from Monday collection.

DOE annual reporting requirements for irternal exposures call for reporting by name all individuals who exceeded 50\% of the applicable annual limits. For uranium uptakes we interpret this to mean individuals who average for the year over 50\% of the applicable organ burdens. The uranium urine samples for individuals are averaged (by hand calculations) over the year and divided by the calculated expected excretion rate corresponding to the maximum permissible organ burder. Since 1967 the highest annual average organ burden for uranium by this technique has never exceeded 30\% for any Los Alamos employee.

For a period of 3 years (1980-1982), K. Coop (Los Alamos Health Physicist) also hand evaluated the uranium intakes using ICRP-30 concepts in terms of the ALI's (Anrusal Limit of Intake), taking into account the assayed 
excretion rates with time. By that procedure the maximum intake for any employee was less than $4 \%$ of the ALI for either depleted or enriched uranium.

\section{ICRP-30 and ICRP Lung Model Uranium Elimination}

Most of the regulatory organizations of the world have accepted or are about to accept ICRP-30 ("Limits for Intake of Radionuclides by Workers") as the basis for regulation. Therefore, it was decided to develop the urinary elimination equations for uranium, based on ICRP-30 and ICRP Lung Model concepts. These equations would then be used to evaluate uranium intake to Los Alamos employees who have submitted urine samples for uranium analysis.

\section{A. Introduction}

Since uranium urine samples are usually collected at intervals of 2 weeks and since urine samples are collected because of the potential for inhalation intakes on an intermittent basis, several simplifications can be made in the modeling by ignoring the small-magnitude, long half-time elimination terms.

While the retention equations given in ICRP-30, Part 1, p. 103, differ significantly from the experimentally determined retention equations given in earlier ICRP publications, those in ICRP-30, Part 1 , will be used in this development. Expressed in terms of that amount of uranium entering the transfer compartment (i.e., the blood), these retention equations are

$$
\begin{aligned}
& R_{B O N E}(t)=0.2 B e^{-\lambda} 20 t+0.023 B e^{-\lambda} 5000^{t}, \\
& R_{\text {KIDNEY }}(t)=0.12 \mathrm{Be}^{-\lambda} \sigma^{t}+0.00052 \mathrm{Be}^{-\lambda} 1500^{t} \text {, and } \\
& R_{\text {OTHER }}(t)=0.12 \mathrm{Be}^{-\lambda} 6^{t}+0.00052 \mathrm{Be}^{-\lambda} 1500^{t} \text {, } \\
& \text { OREANS } \\
& \text { where } \begin{aligned}
\lambda_{6} & =0.693 / 6, \\
\lambda_{20} & =0.693 / 20,
\end{aligned}
\end{aligned}
$$




$$
\begin{aligned}
& \lambda_{1500}=0.693 / 1500, \\
& \lambda_{5000}=0.693 / 5000, \\
& t \text { is measured in days since intake, and } \\
& B \text { is the arnount of uranium entering the blood. }
\end{aligned}
$$

The remainder of the uranium entering the blood (0.535968) is assumed to go directly to excretion (i.e., urine), presumably during the day it entered the transfer compartment.

For the remainder of this development, the fractions retained with 5000-day and 1500-day half-times will be assumed to be permanently retained in the appropriate organs. The uranium eliminated from the bone, kidney, and other organs is, for simplicity, assumed to go directly to excretion (urine).

The amount of uranium entering the transfer compartment (blood) can be related to the amount inhaled, I, in a day, by the ICRP Lung Model. Two classes of uranium compounds (i.e., Class D and Class $W$ ) need to be considered separately because of the differences in transfer times to the blood. Los Alamos experience, based on urinary excretion results, is that the component of Class $Y$ uranium inhaled is insignificant.

For simplicity, in the following treatment, when the ICRP Lung Model requires transfer to the blood with half-times of 1 day or less, it is assumed that the transfer occurs instantaneously. All inhaled materials are assumed to be 1- um AMAD, so that the constants in the standard ICRP Lung Model do not require modification. According to ICRP-30, Part 1, p. 102, the fraction entering the GI tract which goes to the bloord is 0.05 . For the short half-time transfers (i.e., 1 day or less), it is assumed that the partiiioning to the bone, kidney, other organs, and urinary excretion takes place is in such a short time that no additional elimination from the bone, kidney, and other organs takes place during the transfer period. 


\section{B. Class D Transfer}

For Class D materials, all transfers take place with half-times of 1 day or less. If an amount $I_{D}$ of Class $D$ material is inhaled (in 1 day) the short-t me transfer to the blood is listed below.

From N-P region to blood directly

$=0.3 \mathrm{I}_{D} * 0.5=0.15 \mathrm{I}_{\mathrm{D}}$

From N-P region via GI tract to blood

$=0.3 I_{D} * 0.5 * 0.05=0.0075 I_{D}$

From T-B region to blood dizectly

$=0.08 \mathrm{I}_{D} * 0.95=\mathrm{i} .076 \mathrm{I}_{\mathrm{D}}$

From T-B region via GI tract iú ulous

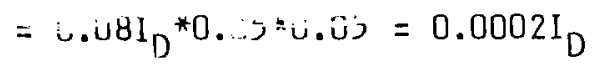

From $P$ region directly to blood

$=0.25 \mathrm{I}_{D} * 0.8=0.2 \mathrm{I}_{\mathrm{D}}$

From $P$ region via lymph node to blood

$=0.25 \mathrm{I}_{D} * 0.2 * 1.0=0.05 \mathrm{I}_{D}$

Total shoit-term transfer to blood $=0.4837 \mathrm{I}_{D}$

of the remaining $0.5163 \mathrm{I}_{\mathrm{D}}$ inhaled, $0.37 \mathrm{I}_{\mathrm{D}}$ is exhaled, and the remainder is eliminated via the GI tract.

The retention equatiors in terms of the inhaled Class D material can be expressed as

$$
\begin{aligned}
& R_{D_{\text {BONE }}(t)}=0.4837 \mathrm{I}_{D}\left(0.2 \mathrm{e}^{-\lambda} 20^{t}+0.023\right), \\
& R_{D_{\text {KIDNEY }}}(t)=0.4837 I_{D}\left(0.12 \mathrm{e}^{-\lambda} 6^{t}+0.00052\right) \text {, and } \\
& R_{\text {DTHER }}^{(t)}=0.4837 \mathrm{I}_{D}\left(0.12 \mathrm{e}^{-\lambda_{6} t}+0.00052\right) \\
& \text { where } \begin{aligned}
{\lambda_{20}}_{20} & =.693 / 20 \\
\lambda_{6} & =.693 / 6
\end{aligned}
\end{aligned}
$$

and the long half-time elimination terms are treated as having infinite half-time.

On the day of intake, the urinary elimination is $0.4837 \mathrm{I}_{\mathrm{D}}{ }_{11} 1.53596=$ $0.259 \mathrm{I}_{\mathrm{D}}$. For later times the urinary elimination is the negative 
derivative of the sum of the retention equations for the Class D materials, or

$$
U_{D}(t)=-\frac{d P_{D}}{d t}=0.4837 I_{D}\left(0.2 \lambda_{20} e^{-\lambda_{20} t}+0.24 \lambda_{6} e^{-\lambda_{6} t}\right) .
$$

To express this result in quantity per liter, it is necessary to divide by 1.4 , if we assume the urinary elimination rate for reference man is $1.4 \mathrm{~L} /$ day, and $\mathrm{I}_{\mathrm{D}}$ can be expressed as $\mu g$ or $\mathrm{pCi}$.

\section{Class W Transfer}

For Class $W$ materials, the situation is slightly more complicated because (according to the ICRP Lung Model) part of the material is transferred to the blood from the three lung compartments, part with half-time of 1 day or less (assumed instantaneous), and part with a half-time of 50 days.

For an amount of Class $W$ material, $I_{W}$, inhaled (in 1 day), the short-time tranefer to the blood is listed below.

From N-P region to blood directly

From N-P region via GI tract to blood

From T-B region to blood direstly

From T-B region via GI tract to blood

From $P$ region via GI tract to sood

$$
\begin{aligned}
& =0.3 \mathrm{I}_{W}{ }^{* 0.1}=0.03 \mathrm{I}_{\mathrm{W}} \\
& =0.3 \mathrm{I}_{W}{ }^{* 0.9 * 0.05}=0.0135 \mathrm{I}_{\mathrm{W}} \\
& =0.08 \mathrm{I}_{W} * 0.5=0.04 \mathrm{I}_{\mathrm{W}} \\
& =0.08 \mathrm{I}_{W}{ }^{* 0.5 * 0.05}=0.002 \mathrm{I}_{W} \\
& =0.25 \mathrm{I}_{W} * 0.4 * 0.05=0.005 \mathrm{I}_{W}
\end{aligned}
$$$$
\text { iotal short-term transfer to blood }=0.0905 \mathrm{I}_{\mathrm{W}}
$$

For an amount of Class $W$ material, $I_{W}$, inhaled (in 1 day), the 50-day half-time transfer to the blood is listed below.

From $P$ region to blood directly

From $P$ region via GI tract to blood

From $P$ region via lymph nodes to blood
$=0.25 I_{W}^{* 0.15}=0.0375 I_{W}$

$=0.25 I_{W}^{* 0.4 * 0.05}=0.005 I_{W}$

$=0.25 I_{W}^{* 0.05}=0.0125 I_{W}$ 
(Note: Actually the material transferred via the lymiph nodes to the blood is furthen delayed by a second 50-day half-time term, hut for simpicity this is ignored.)

Total 50-day half-time transi te blood $=0.055 \mathrm{I}_{\mathrm{W}}$

of the remaining $0.8545 \mathrm{I}_{\mathrm{w}}$ inhaled, $0.37 \mathrm{I}_{\mathrm{W}}$ is exhaled, and the remainder is elin:nated via the GI tract.

The retention equatior, in the bone, kiciney, and cther organs can be considered to be composed of a short-term (S) deposition factor and a long-term ( $L)$, i.e., 50 day half-time, deposition factor:

$$
\begin{aligned}
& R_{W_{B O N E}}=R_{\text {WBS }}+R_{\text {WBL }}, \\
& R_{\text {KIDNEY }_{\text {WIS }}}=R_{\text {WKS }}+R_{\text {WKL }} \text {, and } \\
& R_{\text {WTHER }}=R_{\text {WOS }}+R_{\text {WOL }} .
\end{aligned}
$$

The short-term deposition factors, in terms of the inhaled Class $W$ material, can be expressed (similar to expression for the Class $D$ materials) as

$$
\begin{aligned}
& R_{W B S}(t)=0.0905 i_{W}\left(0.2 e^{-\lambda} 20 t+0.023\right), \\
& R_{W K S}(t)=0.0905 I_{W}\left(0.12 e^{-\lambda_{6} t}+0.00052\right), \text { and } \\
& R_{W O S}(t)=0.0905 I_{W}\left(0.12 e^{-\lambda_{6} t}+0.00052\right),
\end{aligned}
$$$$
\text { where } \begin{aligned}
\lambda_{20} & =0.693 / 20, \\
\lambda_{6} & =0.693 / 6,
\end{aligned}
$$

and the long half-time elimination terms are treated as having infinite half-times. 
The retention equations for the 50-day half-time deposition factors are somewhat more compliceted hecause of the dynamics of the 50-day half-time uptake to the organs while the material is also being eliminated. Therefore, the derivation of the retelicion equations for the 50-day half-time build-up components must be obtained from the differential equations describing the process.

To simplify the presentation, the three organs will be treated independently. The rate of elimination (of the 50-day half-time build-up component) for the bone (i.e., $d R_{W B L} / d t$ ) is the sum of two terms. The first term is the product of the rate of build-up in the bone and the fraction inhaled going to the bore with the 50-day half-time, i.e.,

$$
{ }_{50} e^{-5} 50^{t} * 0.2 * 0.0551_{w}=0.011 I_{w}{ }^{\prime} 50^{e^{-i} 50^{t}} \text {, where }{ }_{50}=0.693 / 50 \text {. }
$$

The second term is the neqative (indicates elimination) rate of change of the amount in the bone, i.e., $-20^{R_{W B L}}$. Thus, the differential equation is

$$
\frac{d f_{W B L}}{d t}=0.011 I_{W} \quad:_{50} e^{-i} 50-i_{20} R_{W B L} .
$$

Integration of this expression with the appropriate boundary conditions $\left[\right.$ i.e., $\left.R_{W B L}(0)=0\right]$ yields

$$
R_{W B L}(t)=0.011 I_{W} \frac{\lambda_{50}}{\left(\lambda_{20}-\lambda_{50}\right)}\left(e^{-\lambda_{50}}{ }^{t}-e^{-\lambda_{20} t}\right) .
$$

Similarly, the differential equations for the elimination of the 50-day half-time build-up component in the ridney and other organs is

$$
\frac{d R_{W K L}}{d t}=\frac{d R_{W O L}}{d t}=0.0066 I_{W} \lambda_{50} e^{-\lambda} 50^{t}-\lambda_{6} R_{W K L} .
$$

Integration of this expression with the appropriate boundary conditions (i.e., $R_{W K L}(0)=R_{W O L}(0)=0$ ) yields 


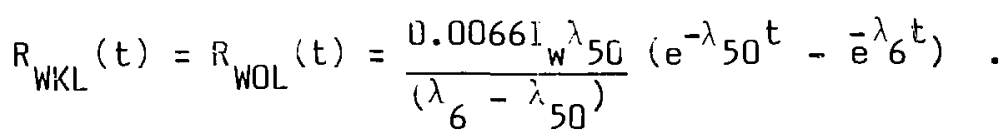

Combining these results the complete approximate organ retention equations are

$R_{W_{B O N E}(t)}=0.0905 I_{W}\left(0.2 e^{-\lambda} 20^{t}+0.023\right)+\frac{0.011 I_{W} \lambda_{0}}{\left(\lambda_{20}-\lambda_{50}\right)}\left(e^{-\lambda_{50}}{ }^{t}-e^{-\lambda_{20} t} ;\right.$,
$R_{W_{\text {KIDNEY }}(t)}=0.0905 I_{W}\left(0.12 e^{-\lambda_{6} t}+0.00052\right)+\frac{.0066 I_{W} \lambda_{50}}{\left(\lambda_{6}-\lambda_{50}\right)}\left(e^{-\lambda_{50}}-e^{-\lambda_{6} t}\right)$,

and

$R_{W_{\text {UTHER }}(t)}=0.0905 \mathrm{I}_{W}\left(0.12 \mathrm{e}^{-\lambda_{6} t}+0.00052\right)+\frac{.0066 \mathrm{I}_{w} \lambda_{50}}{\left(\lambda_{6}-\lambda_{50}\right)}\left(\mathrm{e}^{-\lambda_{50} t}-\mathrm{e}^{-\lambda_{6} t}\right)$.

On the day of intake of the Class $W$ material, the urinary elimination is $0.0905 \mathrm{I}_{w} * 0.53596=0.0485 \mathrm{I}_{\mathrm{w}}$. For later times the urinary elimination is the sum of two terms: (1) the sum of product of the appropriate organ decay constants times the appruximate organ retention equations; and (2) the directly eliminated fraction (0.53596) of the 50-day half-time material entering the blood (i.e., $0.055 \lambda_{50} e^{-\lambda} 50^{t}$ ), for the Class $W$ material, where the constant retention terms have been dropped from the retention equations for simplicity, or

$$
\begin{gathered}
U_{W}(t)=\lambda_{20}\left\{0.0965 I_{W}\left(0.2 e^{-\lambda_{20} t}\right)+\frac{0.011 I_{W} \lambda_{50}}{\left(\lambda_{20}-\lambda_{50}\right)}\left(e^{-\lambda_{50} t}-e^{-\lambda_{20} t}\right)\right\} \\
+2 \lambda_{6}\left\{0.0905 I_{W}\left(0.12 e^{-\lambda_{6} t}\right)+\frac{0.0066 I_{W} \lambda_{50}}{\left(\lambda_{6}-\lambda_{50}\right)}\left(e^{-\lambda_{50} t}-e^{-\lambda}{ }_{6} t\right)\right\} \\
+0.53596 * 0.055 I_{W} \lambda_{50} e^{-\lambda_{50} t} .
\end{gathered}
$$


Changes in Uranium Sampie Collection and Evaluation Procedures

To provide urine assay data which will reduce the present overestimations of uranium uptake, urine sample collection times were changed from Fridays to Mondays, before the personnel start work. A memo to all personnel on the uranium urine assay program was prepared informing them of the change and the reasons for the change. This procedure was initiated on $8 / 9 / 83$.

To eliminate hand evaluation of employees' uranium exposures, it was decided to produce a set of computer programs to accomplish this task. Sir.ce urine assays are performeit for either depleted uraniuin or enriched uranium, complementary programs had to be produced for each analysis type. The first pair of programs use the total annual (depleted or enriched) uranium urine assay file from the anglysis group. Ali an!a!yis results recorded as "less than" [designated by the letter $L$, and representing the Minimum Detectable Activity (MDA)] are convarted to "minus" the magnitude of the recorded value, so that the evaluation program can read the data with a numeric format. In all calculatiors involving these "iess than" values, the "absolute value" was used, un] ss nuted utherwise. Checks are made for improperly recorded dates, sample types, and analysis result units. Messages are printed describing the detected data entry errors. The data are sorted by employee identification numbers ( $Z$-numbers) with subsort by sample date. A working file of the sorted data is saved. This working file is reread, and cor iecutive samples are checked for idenicical dates. All pairs of data with identical dates are listed and the complete sorted file is listed.

The listing of the sorted file is checked by eye for incorrect nairings of Z-numbers and names. The Z-number sorted file is then edited to correct Z-number/name errors and any other errors deterted by the sorting program. Identical analysis results for the same date (i.e., duplicate entries) are elininated by editing. When two different results are reported for the same vate, they are replaced by the average of the reported results (unless one of the analyses was performed by radiometric or fluorometric analysis, in which case the radiometric or fluorometric result is retained as the more reliable.)*

* Since 1978 , to reduce the analysis complexities, uranium urine assays have teen performed by "delayed neutron counting" technique, which requires prior sperification of depleted or enriched uranium evaluation according to the employee's work location or material handled. 
Prior to writing the evaluation programs, severa decisions had to be made on how to handle actual urine assay results in ragard to assumed or derived intake dates and partitioning of Class $D$ and $C$ Following a single acute exposure, when three consecutive, positive, Jecreasing urine assay results exist, the ICRP-30-bsed elimination equations permit estimation of the date of intake and the amants of both Class $D$ and Class $W$ material taken in. During 1979 through $19 \mathrm{~g} 2$, examination of the edited urine assay results showed orily 12 instances of 3 consecutive, positive, decreasing urine results. These 12 sets of data were used as input to the simultaneous solution of the combined elimination equations for any arbitrary mixture of Class $D$ and Class $W$ materials, but in each case the data did not fit the model (i.e., no solution was obtained). Therefore, it was concluded that in none of these cases did the urire data represent a single acute exposure which followed the ICRP-30 elimination equations: and probably the urine data was the result of multiple exposures. Since these urine data provided no clue as to the partitioning of the Class $D$ and Class $W$ materials, the first decision was to perform the exposure calculations individually for both Class D and Class W materials.

The second decision was to perform calculations of three measures of exposure: (1) the total annual intatie, (2) the fraction of the allowable excretion rate for chronic intake at the DAC (derived air concentration) represented by the average urine excretion for the year, and (3) the maximum single intake for comparison with the nephrotoxic limit for Class D material. Two computer listings were planned, the first giving the detailed calculational results for each urine sample for each individual, and the second giving the total intake, fraction of allowable urine excretion rate, and the fractional nephrotoxic limit for all persons sampled.

Since the ICRP-30-based elimination equations are in terms of total excretion per day, the recorded urine assay results were converted from $\mathrm{pCi} / \mathrm{L}$ and $\mu \mathrm{g} / \mathrm{L}$ to $\mathrm{pCi} /$ day and $\mu \mathrm{g} /$ day by multiplying by $1.4 \mathrm{~L} /$ day (assuming the "Reference Man" urinary excretion rate). The actual dales of the urine samples have been converted to integer dates since $1 / 1 / 43$ to facilitate calculations.

Using the ICRP-30-based elimination equations, subroutines $[F C D(t)$ and $F C W(t)]$ were prepared for both Class $D$ and Class $W$ materials to calculate the fraction of an acute intake excreted on day $t$ after the intake. These 
subroutines are applied in the predictor mode, the elimination mode, and the j.ntake mode.

i. The Predictor Mode

In this mode the intervening time (IVT) from the positive urine result to the next "minus" value (i.e., less than MDA value) was calculated. If the Cla:s D intake occurred on the day of the positive sample, the maximum urine value (EMXUD), which could have occurred on the date of the positive sample, would have been the product of the absolute value of the "less than MDA" sample times the ratio FCD(0)/FCD(IVT). If the Class $D$ iritake occurred on the day before the positive sample, the probable maximum urine value (PMXUD), which could have occurred on the date of the positive sample, would have been the product of the absolute value of the "less than MDA" sample times the ratio FCD(1)/FCD (IVT+1). Similar expressions apply for assumed Class $W$ intakes. EMXUD is simply calculated and printed in the detail listing. PMXUD is used to decide how to calculate the intake, depending on whether the collection time was just before leaving work (i.e., prior to $8 / 9 / 83$ ) or befure starting work.

B. The Elimination Mode

After an intake has been calculated, this mode is used to calculate the predicted excretion on the dates of subsequent samples (through the next "less than MDA" sample). In order to reduce the overestimation of additional intakes, the actual reported urine results are reduced by the amount of the predicted excietion rates. The resulting adjusted excretion rates (ARESO and ARESW) are printed on the detail listing and are used to calculate the additional intakes.

C. The Intake Mode

This mcde of application is used to calculate the incremental intakes (TAKD or TAKW). For the first positive urine result, no previous intake existed, and the actual urine result is assigned to the ARESD.

When ARESD is greater than or equal to PMXUD, the intake is assumed to occur on the date of the urine sample or or a date 1-3 days before the urine sample date. Prior to $8 / 9 / 83$, if the urine sample was submitted on any day except Saturday or Sunday, the intake (TAKD) is calculated as 
occurring on the date of the urine sample. (For a Saturday or Sunday urine sample, the intake is assumed to have occuraed the previous Friday.) After 8/9/83, when the urine samples are submitted before starting work, if the sample was submitted on any day except Sunday or Monday, the intake (TAKD) is calculated as occurring the day before ths date of the urine sample. (For a Sunday or Monday urine sample, the intake is assumed to have occurred on the previous Friday.)

When ARESD is less than PMXUD, the intake is uscialiy assumed to have occurred 7 days before the urine sample was subitted. This date would usually be midway between the two extreme possibilities of the intake for biweekly sampies occurring the day after the previous sample (resulting in maximum caleulated intake) or occurring the day before the current urine sample was submitted (resulting in minimum calculated intake), Exceptions are made when less than 7 days passed between the urine sample being evaluated and the previous urine sainple. In these cases the intake is assumed to have occurred on the day of the previous sample (with adjustments made for weekends to the Friday before the weekend).

When a negative value of ARESD occurs, i.e., when the sum of the expected excretion from previously calculated intakes exceeds the actual measured urine sample, a negative intake (TAKD) is calculated. This procedure is used to reduce the overestimate of the previous TAKD's when it is surmised that the previous urine sample may have been contaminated.

A similar procedure is used for the Class $W$ intake (TAKW) calculatioris using adjusted Class W urine results (ARESW).

The computer program evaiuates the exposure for one person before proceeding to the next person. Urine samples are evaluated sequentially from the earliest dated sample in a given year to the last sample that year. Until the first fositive urine sample is encountered, the "minus" urine results (i.e., the less-than-MDA results) are treated as zero values, giving zero incremental intakes for those samples. After the first positive sample is encountered, a subset of urine samples is formed and includes all ronsecutive positive samples plus the next "minus" sample. [If the final sample of the year was a positive sample, to permit a calculation of intake for that sample, it was necessary to "fabricate" a "last sample plus one" with a value of 
"minus" the MDA (i.e., less than the MDA), occurring 14 days after the last actual sample.]

Each subset of samples is evaluated sequentially as described above fur the positive urine results. When the last sample of the subset is encountered, the procedure is modified slightly. Since the last sample of the subset is only known to be "less than the MDA," the sum of the expected urine excretions from the previously calculated intakes of this subset is compared with the magnitude of the MDA. If this sum is less than the magnitude of the MDA, the intake (TAKD or TAKW) is given a zero valise (and ARESD or ARESW is set to zero). If this sum exceeds the magnitude of the MDA, ARESD Or ARESW is se. equal to "minus" this surn diminished by the MDA. A negative TAKD or TAKW is then calculated.

This procedure is repeated until all samples for the individual or: evaluated. The total intake during the year is the suin of the TAKD's (or TAKW's for Class $W$ material). The average urine excretion during the year is the sum of the ARESD's (and ARESW's for Class $W$ material) divided by the number of actual urine samples submitted. To determine the largest single incremental intake during the year, the TAKD's (for Class D Material only) are examined sequentially to determine the largest value, diminished by an immediately following negative value. If the next TAKD is positive, the TAKD is not reduced (since there is no evidence of urine scimple contamination).

Because the units of analysis differed for the reported results of enriched and depleted uranium in urine and because the MDA's differed for the materials, separate but similar prograns had to be prepared for the two types of analyses. In the summary listings for each type arialysis, the fractional allowed annual limit of intake, fractional allowed average urine excretion, and fraction of nephrotoxic limit are also tabulated. The fractional quantities are obtained bf dividing the calculated values by the appropriate number from Table 1.

\section{Suminary of Uran.um Exposure Calculations}

All Los Alamos depleted-uranium urine assay data were prepared as computer files. The enriched-uranium urine assay data from 1959 through 1983 have also been made into computer files. The earlier enriched-uranium data is being processed to prepare computer files, as time and funding permits. All. 
TABLE 1

LIMITS OF URANIUM EXPOSURE

(Based on ICRP-30 and ICRP Lung Model CE: $x^{2}=$ ept3)

\begin{tabular}{|c|c|c|c|c|}
\hline $\begin{array}{l}\text { TYPE OF } \\
\text { LIMIT }\end{array}$ & $\begin{array}{l}\text { CLASS D M } \\
\text { ENRICHED (95\%) } \\
\text { UITANIUH }\end{array}$ & $\begin{array}{l}\text { LEPLETED } \\
\text { URANIUM }\end{array}$ & $\begin{array}{l}\text { CLASS W M } \\
\text { ENRICHED (95\%) } \\
\text { URANIUM }\end{array}$ & $\begin{array}{l}\text { IAL } \\
\text { DEPLETED } \\
\text { URANIUM }\end{array}$ \\
\hline $\begin{array}{l}\text { h.iaral Limit of } \\
\text { Intake (A! } i)\end{array}$ & $1.35 \times 10^{6} \mathrm{pCi}$ & $2890 \mathrm{mg}$ & $0.81 \times 10^{6} \mathrm{pCl}$ & $1 / 3 \mathrm{jg}$ \\
\hline $\begin{array}{l}\text { Allowable Steady- } \\
\text { 5tate Excretion } \\
\text { for Honday Sample }\end{array}$ & $1100 p C i / d a y$ & $2.36 \mathrm{mg} / \mathrm{dgy}$ & $100 \mathrm{pCi} /$ day" & $0.214 \mathrm{mg} / \mathrm{day} "$ \\
\hline $\begin{array}{l}\text { Nept stoxic } \\
\text { Limit (Single- } \\
\text { Day Intake) }\end{array}$ & $1.07 \times 10^{6} \mathrm{pCi} /$ day & $15.1 \mathrm{mg} / \mathrm{day}$ & ** & $* *$ \\
\hline
\end{tabular}

\footnotetext{
*These values for Class $W$ materials were derived in the same way that the values for Clasg $D$ materisls (given in the text).

- Neptrotoxic limits are not applicable for Class $w$ materials as noted in the text.
}

of the existing computerized uranium urine assay records have been processed by the program described above for each year's data.

Examination of these calculations shows two generalized findings. First, Class $W$ intakes range from 3 to 6 times the calculated Class $D$ intakes for both depleted and enriched uranium. To be conservative we will use the Class $W$ result to satisfy the DOE reporting criteria in the future. Second, the fractional ALI calculations appear to be a better representation of uranium exposure than the iractional allowed excretion-rate calculations. Two factors can adversely affect the fractional allowed excretion-rate calculations: few sample analysis results and (2) one or two very high analysis results. When there are cnly a few analysis results for an individual during a year, the average obtained is not truly representative of the annual average. (The person involved probably only had a casual, single potential exposure for a short time period and submitred samples only for that time interval.) When 
one or two very high results occur, followed by many low or less than MDA results, again the average is not representative of a continuous chronic exposure, which the annual averaging method purports to represent. When there were no extremely large urine assay results and the person regularly submitted samples throughout the year, the agreement between the two measures of exposure was generally within $\pm 50 \%$.

Table 2 presents the highest calculated annual uranium exposures in terms of percent of the allowable values. The misleading effect of few urine samples and one or two high urine results on the calculation of average annual excretion rates is identified by footnotes to the tablt. Only by examination of the detaileo calculations was it possible to determint the cause of the apparently excessive (calculated) average annual excretion rates. Usirig the fractional ALI as the appropriate indicator of uranium exposure, it is seen that no uranium exposures have been detected at Los Alamos which would have required being reported to DOE under the 1983 reporting criteria.

During the 1950-1967 period, intakes of depleted uranium were more frequent than in later years. A continuing program to reduce uranium aerosols in chemical, metaliurgical, and machining operations has effectively reduced the frequency and magnitude of personnel uranium exposures since that time period. This observation is confirmed by the single-day acute intake calculations. From 1949-1958 there were 24 occasions when individuals exceeded the nephrutoxic limit on intake; from 1959-1968 there were five such occasions, and since 1969 there was only one instance of exceeding the nephrotoxic limit.

Again based on the fractional ALI calculations, exposures to enriched uranium have been at a relatively constant leivel from 1959 through 1981. The slight reduction in enriched-uranium exposures for 1982-1983 may well fall within the statistical variation seen in the earlier years. 
TABLE 2

SUMMARY OF HIGHEST \% CALCULATED ANNUAL URANIUM EXPOSUREJ

MATERIAL CLASS AND REPORTING PARAMETER

Largest Class D : ALI

Largest Class W: ALI

Largest Class D\% ALI (1983)

Largest Class W\% ALI (1983)

Largest Class D $\%$ Allowed Average Excretion Rate

Largest Class W

: Allowed Average

Excretion Rate

Largest Class D

$\%$ Allowed Average

Excretion Rate (1983)

Largest Class $W$

: Allowed Average

Excretion Rate (1983)
EXPOSURES TO

ENRICHED URANIUM

(1959-1983)

$3.6(1967)$

$15.9(1963)$

0.9

0.5

4.5

2.1

30.* (1978)

13. (1950)

$330 . *(1978)$

140.** (1950)

2.1

0.3

$24 . * * *$

3.9

*Calculated from 2 high analyses, followed by 17 analyzes of less than MDA.

**Calculated from 1 high analysis.

***Calculated from 4 analyses. 


\section{REFERENCES}

1. "Applications of Bioassay for Uranium," WASH-1251, U. S. Atomic Energy Commission, June 1974.

2. S. H. Bassett et al., "The Excretion of Hexavalent Uranium Following Intravenous Administration, II, Studies on Human Subjects," UR-37, University of Rochester, 1948.

3. S. R. Bernard and E. G. Struxness, "A Study of the Distribution and Excretion of Uranium in Man. An Inter im Report," ORNL-2304, Dak Ridge National Laboratory, 1957.

4. "Evaluation of Radiation Doses to Body Tissues from Internal Contamination due to 0ccupational Exposure," ICRP-10, Pergamon Press, 1968.

5. "Limits for Intakes of Radionuclides by Workers," in Annals of the lCRP, ICRP-30, Pergamon Press, 1978.

6. ICRP Task Group on Lung Dynamics, "Deposition and Retention Models for Internal Dosimetry of the Human Respiratory Tract," Health Physics 12 , $173-207,1966$.

7. H. C. Hodge, J. W. Stannard, and J. B. Hursh, Editors, Uranium, Plutonium, Transplutonic Elements, Handbook of Experimenta? Tharmacology, XXXVI, Springer-Verlag, 1973.

8. Report of ICRP Committee II, "Permissible Dose for Internal Radiation (1959)," Рergamon Press, 1960.

9. "Reference Man," ICRP-23, Peroamon Press, 1975.

10. I. S. Eve, "Some Suggested Maximum Permissible Single Intakes of Uranium " Health Physics 10, 733-776, 1964.

11. "Recommendations of the International Commission on Radiulogical Protection (Revised 1962)," ICRP-6, Pergamon Press, 1964.

12. C. Voegtlin and H. C. Hodge, Pharmacology and Toxicology of Uranium Compounds, Chap. 26, McGraw-Hill, 1953.

13. S. Jackson, "The Interpretation of Data on Radionuclides in Urine, Part 1: Uranium," AHSB(RP)R15, United Kingdom Atomic Energy Authority, 1962. 